\title{
EDUCAÇÃO AMBIENTAL EM ESPAÇO NÃO FORMAL: A ATUAÇÃO DA IGREJA CATÓLICA
}

\author{
Silvana de Souza Moraes ${ }^{1}$, Gerson Luiz de Moraes $^{2}$, Rosane Aparecida Gomes Battistelle ${ }^{3}$
}

\section{RESUMO}

Este artigo tem por objetivo analisar a atuação da Igreja Católica, especialmente no Brasil, quanto à conscientização e educação ambiental não formal. Para isso o artigo apresenta uma descrição sobre as Campanhas da Fraternidade desenvolvidas pela Igreja Católica no Brasil, em especial a Campanha da Fraternidade de 2016, fazendo a análise de como os temas são apresentados e discutidos nos materiais didáticos utilizados na formação das pessoas, por meio de agentes voluntários a serviço da igreja. Apresenta-se também uma revisão dos documentos oficiais da instituição referentes ao tema educação e meio ambiente que embasaram os materiais desenvolvidos no Brasil e utilizados nos encontros de formação.

PALAVRAS-CHAVE: Educação ambiental. Educação não formal. Campanha da fraternidade.

\section{ABSTRACT}

This article aims to analyze the role of the Catholic Church, especially in Brazil, as the awareness and non-formal environmental education. For this, the article presents a description of the Brotherhood of campaigns developed by the Catholic Church in Brazil, especially the Brotherhood Campaign 2016, making the analysis of how the issues are presented and discussed in textbooks used in training people through volunteer agents in the service of the church. It also presents a review of official documents of the institution on the topic environment and education that supported the materials developed in Brazil and used in training meetings.

KEY-WORKS: Environmental education. Non-formal education. Campaign fraternity.

\section{INTRODUÇÃO}

Questões ambientais são apresentadas e, por vezes discutidas com a população devido à urgência em se ter ações coletivas que busquem soluções para situações cada vez mais comuns como a falta de acesso à agua potável, a dependência no uso de energia não renovável, as consequências das mudanças climáticas decorrentes da ação do homem e o surgimento de doenças causadas pela má gestão dos resíduos. Para que haja mudanças nas situações atualmente vigentes se fazem necessários, além de investimentos financeiros e de comprometimento dos governantes, a mudança no estilo de vida das pessoas, que conscientes estejam preparadas para efetuar tais mudanças, como afirmam documentos do FBOMS (Fórum Brasileiro de ONGs e Movimentos Sociais para o Meio Ambiente e o

1 Mestra em Engenharia de Produção, Pós-graduada em Gestão integrada e Gestão de Pessoas, Licenciada em Letras.

2 Mestrando em Letras, graduado em Letras e Pedagogia.

3Prof Dr da Faculdade de Engenharia da UNESP campus Bauru. 
Desenvolvimento) e o IPCC (2014) que declara que mudanças das condições ambientais dependem também da escolha de um estilo de vida e comportamentos sustentáveis, no entanto, para que seja possível esta escolha a população deve estar consciente da importância de fazê-lo.

Para possibilitar esta conscientização, programas de Educação Ambiental são implantados em instituições públicas e privadas de ensino, empresas, organizações não governamentais e sem fins lucrativos, como igrejas, sindicatos, associações de moradores e outros, sendo um valioso instrumento para o ensino e a aprendizagem do tema Meio Ambiente (PCN, 1997).

Diante disso, este trabalho tem por objetivo analisar ações desenvolvidas pela Igreja Católica no âmbito da Educação Ambiental por meio de campanhas que visam, além da conscientização ambiental, à consciência social das mudanças necessárias para que o meio ambiente seja preservado, assim como o conhecimento das implicações da não mudança. Esta análise pautou-se em documentos oficiais da igreja sobre o tema, em especial a encíclica papal "Louvato Si", que apresenta uma profunda análise do tema ambiental e os materiais e publicações referentes à campanha da fraternidade do ano de 2016, cujo tema é "Casa comum, nossa responsabilidade", focando a responsabilidade coletiva diante do planeta Terra.

\section{REFERENCIAL TEÓRICO}

Para embasar a discussão ora proposta foram revisados artigos científicos, livros, legislação e publicações da Igreja Católica sobre os temas Educação, o histórico da Igreja Católica como agente social no Brasil e no mundo e os temas ambientais abordados pela igreja por meio da Campanha da Fraternidade, especialmente a do ano de 2016, cujo tema foi "Casa comum, nossa responsabilidade".

\section{EDUCAÇÃO AMBIENTAL}

De acordo com Art. $1^{\circ}$ da Lei 9.795, de 27 de abril de 1999, educação ambiental é o processo por meio do qual o indivíduo e a coletividade constroem valores sociais, conhecimentos, habilidades, atitudes e competências voltadas para a conservação do meio ambiente, bem de uso comum do povo, essencial à sadia qualidade de vida e sua sustentabilidade. A mesma lei determina que a responsabilidade pela educação ambiental é da rede oficial de ensino, das empresas, entidades de classe, instituições públicas e privadas. 
Após a Lei 9.795/99, a educação ambiental que estava restrita aos ambientes escolares passou a ser considerada também em todos os espaços sociais, tendo, desta forma, a possibilidade de alcançar públicos não frequentadores da rede oficial de ensino, o que colabora com o onjetivo da educação explicitado por Miranda, Schall e Modena (2007) que é de ser o da participação social dos excluídos, inserindo-os numa sociedade que pretende ser igualitária. Os excluídos no contexto da educação ambiental podem ser entendidos também como público que não teve em sua formação escolar o contato com a educação ambiental, visto que a legislação brasileira só passou a considerar esta preocupação em 1999, após esta ter surgido contexto mundial a partir da década de 70 . Neste aspecto o ensino não formal é entendido como ações e práticas educativas que promovem a sensibilização e conhecimento da coletividade para as questões ambientais e à sua organização e participação na defesa da qualidade do meio ambiente (MIRANDA, SCHALL E MODENA, 2007). Para Bianconi e Caruso (2005), a educação não formal define-se como qualquer tentativa educacional organizada e sistemática que se realiza fora dos quadros do sistema formal de ensino, já Gohn (2006) define como aquela que se aprende via os processos de compartilhamento de experiências, principalmente em espaços e ações coletivos cotidianos.

No entanto, há desafios em formular uma educação ambiental em nível não formal que seja crítica e inovadora, um ato político voltado para a transformação social, com enfoque numa perspectiva de ação holística que relaciona o homem, a natureza e o universo onde o homem reconhece-se responsável pela degradação dos recursos naturais finitos (JACOBI, 2003). Saito (2011) afirma que é vital a prática de uma Educação Ambiental que promova a participação e a cidadania por meio da mobilização consciente, reflexiva e fundamentada nos conhecimentos científicos e nas experiências exitosas. Neste sentido, organizações como sindicatos, associações e igrejas tem se mobilizado para enfrentar este desafio.

O documento Educação, Igreja e Sociedade da CNBB (2014) destaca a necesssidade de a Igreja Católica envolver-se ainda mais na questão educacional, enfatizando as campanhas da Fraternidade como um dos processos exitosos de educação desenvolvidos pela instituição.

\section{A IGREJA CATÓLICA COMO AGENTE SOCIAL}

A Igreja Católica destaca-se como instituição que desenvolve programas e ações voltados às questões sociais mundiais e locais. Zambom (2005) afirma que a Doutrina 
Social da Igreja é um corpo doutrinário que se formou a partir da Revolução Industrial (fins do século XVIII) e vem acompanhando a história do homem em sua questão social, sendo que durante a Revolução Industrial se pronunciou contra a exploração do capital, denunciando a exploração a qual os trabalhadores eram submetidos.

Em 1891, a encíclica Rerum Novarum (1891) trouxe questões sociais atuais como intervenção do Estado na relação patrões e operários, o direito de associação dos trabalhadores, os salários mais justos, crítica ao excesso de horário de trabalho e os abusos praticados às mulheres e crianças operárias, propondo discussões sobre a proteção do trabalho dos operários e enfatizando que o governo é para os governados e não vice-versa, reafirmando a comunhão dos bens da natureza, a dignidade do trabalho, e a responsabilidade da posse e uso das riquezas e as obrigações dos operários e dos patrões.

Bulla (2003) destaca a atuação da Igreja Católica em 1936 com a expansão das instituições católicas assistenciais e educativas, como as universidades católicas, que foram significativas na formação de pessoal para a realização do trabalho social nas instituições assistenciais nascentes.

No Brasil a atuação da igreja durante a ditadura militar foi expressiva quando se tornou praticamente a única voz contra o regime ditatorial e desumano em que o país viveu, além de seu papel fundamental na consolidação da Carta Constitucional, em 1988 (ZAMBOM, 2005). A estrutura da Igreja para a prática de sua ação social no país conta com a CNBB (Conferência Nacional dos Bispos do Brasil), pastorais, movimentos e organismos sociais, tendo as ações da Igreja Católica uma grande expressão nacional no enfrentamento da questão social, como destaque para a atuação e os resultados alcançados pela Pastoral da Criança.

Atualmente, um forte movimento social da Igreja Católica ocorre pela realização da Campanha da Fraternidade, que segundo a CNBB tem como objetivos permanentes despertar o espírito comunitário e cristão, comprometendo-se na busca do bem comum; educar para a vida em fraternidade, a partir da justiça e do amor, em vista de uma sociedade justa e solidária.

A Campanha da Fraternidade é realizada anualmente pela Igreja Católica, abordando e promovendo a discussão de temas de grande importância para a vida social. Iniciou-se em 1962 na Arquidiocese de Natal, e a partir de 1964 ganhou caráter nacional. Os temas abordados focaram as questões da Igreja e do povo do Brasil, e pode ser dividido em três fases. A primeira, de 1964 a 1972, refletiu sobre situação de injustiça, de exclusão e de crescente miséria, aspectos bem determinados da realidade socioeconômica e política 
brasileira, e buscou o restabelecimento da justiça e da fraternidade como compromisso urgente da fé, com temas ligados à renovação da igreja, fraternidade e co-responsabilidade, participação, serviço e vocação, buscando despertar no fiel o sentido de pertença e a responsabilidade do cuidado amoroso com o outro.

A segunda fase, de 1973 a 1984, abordou de forma ampla as questões sociais do Brasil, denunciando o pecado social e promovendo a justiça, contribuindo por meio da Campanha da Fraternidade, para que o chamado à conversão se estendesse ao âmbito comunitário e social, despertando as consciências para as graves injustiças existentes nas estruturas do país, incentivando a busca de ações transformadoras. Temas como a fraternidade na família, no trabalho e reflexões sobre as condições de saúde, violência, educação e migrações fizeram parte das campanhas nesta fase.

Na terceira fase, a partir de 1985, os temas apresentados voltam-se para as situações existenciais do povo brasileiro como a luta pela terra, por habitação, alimento e trabalho, além de olhar para excluídos da sociedade como os menores abandonados, encarcerados e idosos. Discutiu também temas relacionados à saúde, ao uso de drogas, à situação da mulher, juventude, família, política, pessoas com deficiência, segurança pública, economia, tráfico humano e meio ambiente.

\section{CAMPANHAS DA FRATERNIDADE AMBIENTAIS}

Nestes últimos 30 anos a igreja católica, abordou durante a quaresma, uma série de temas sociais e humanitários, e a partir do ano de 1979, a campanha da fraternidade propôs, como iniciativa, uma discussão sobre temas ambientais e a necessidade dos cristãos enxergarem a natureza (criação de Deus) com maior responsabilidade. A campanha da fraternidade de 1979 teve como objetivo geral discutir, em âmbito nacional, um assunto que nunca tinha sido abordado antes, comprovando o pioneirismo da igreja em provocar uma reflexão responsável acerca da necessidade do cuidado com o planeta Terra, contribuindo para uma maior consciência sobre a importância desse assunto, sendo este o grande mérito da Campanha de 1979, que enfrentou grandes dificudades e incompreensão pelo ineditismo do tema. Conforme a afirmação da CNBB sobre a campanha de 1979, esta enfatizou que a ecologia chama a uma nova mentalidade de superação do egoísmo, da ganância de possuir mais a qualquer preço. Destaca a importância da preservação e conservação do ar, da água, da flora e da fauna, elementos necessários ao próximo. Para a CNBB, trata-se de readquirir o respeito carinhoso e a admiração contemplativa das belezas naturais. A carta do papa João Paulo II naquela ocasião enfatizou o papel educacional 
necessário para a mudança de atitude em relação ao meio ambiente, afirmando que para que a natureza seja mais respeitada há que se renovar ou criar uma nova mentalidade, educar-se e educar constantemente para o amor cristão da natureza.

A segunda vez que a Campanha da Fraternidade discutiu um tema ambiental foi em 2004 em que a Igreja Católica novamente enfatizou a necessidade do olhar cuidadoso para a natureza, trazendo o cuidado com a água como tema da campanha e tendo como objetivo conscientizar a sociedade que a água é fonte da vida, uma necessidade de todos os seres vivos e um direito da pessoa humana, desta e de outras gerações. A carta do então Papa João Paulo II ao povo brasileiro, afirmou que a água é instrumento vital, imprescindível para a sobrevivência e, portanto, um direito de todos, destacando a necessidade de atentar para os problemas decorrentes da sua escassez em todas as partes do mundo. Por ser um recurso limitado, seu uso racional exige a colaboração de todos os homens, das autoridades governamentais para conseguir uma proteção eficaz do meio ambiente, sendo uma questão que deve ser interligada à valorização da vida e ao respeito pelos direitos e pela dignidade de todos os seres humanos.

Na Campanha da Fraternidade de 2007 a questão ambiental mais uma vez foi discutida pela Campanha da Fraternidade, quando a igreja chamou a atenção para o território amazônico e seus habitantes. O objetivo foi de conhecer os valores e a criatividade dos povos da Amazônia e as agressões que sofrem por causa do modelo econômico e cultural, chamando a todos os fiéis ao respeito, à conversão, à solidariedade, a um novo estilo de vida. O Papa Bento XVI em carta enviada ao povo brasileiro afirmou que a fraternidade efetiva com as populações amazônicas é compromisso de todos, defendendo e promovendo a vida que se manifesta com tanta exuberância na Amazônia, destacando que o vasto território constitui um patrimônio comum que, por sua realidade humana, sociopolítica, econômica e ambiental, requer especial atenção da Igreja e da sociedade brasileira.

Em 2011 as mudanças climáticas foram o tema da Campanha da Fraterniidade que teve como objetivo contribuir para o aprofundamento do debate e busca de caminhos de superação dos problemas ambientais provocados pelo aquecimento global e seus impactos sobre as condições da vida no planeta. Em sua carta o Papa Bento XVI afirmou que para uma relação sadia com o mundo é necessário que o homem se conscientize de sua condição de criatura, reconhecendo que não é Deus, mas a sua imagem, buscando ser a presença de Deus em todas as criaturas, especialmente, na pessoa humana que o rodeia, 
afirmando a necessidade da defesa da vida humana, da família capaz de gerar vida e a defesa daqueles que são excluídos e marginalizados pela sociedade.

Voltando às questões ambientais, no ano de 2016 a igreja estipulou como objetivo da Campanha da Fraternidade a busca do direito ao saneamento básico para todas as pessoas e o empenho em exigir políticas públicas e atitudes responsáveis de governantes e dos cidadãos que garantam a integridade e o futuro do Planeta, do país, de cada município, denominado na campanha como "Casa Comum", designando o local de convivência e suas interações.

Figura 1 - Campanhas da fraternidade sobre o meio ambiente

\begin{tabular}{|l|l|l|}
\hline Ano & Tema & Lema \\
\hline CF 1979 & Por um mundo mais humano & Preserve o que é de todos \\
\hline CF 2004 & Fraternidade e água & Água, fonte de vida \\
\hline CF 2007 & Fraternidade e Amazônia & Vida e missão neste chão \\
\hline CF 2011 & Fraternidade e a Vida no Planeta & A criação geme em dores de parto (Rm 8,22) \\
\hline CF 2016 & "Casa comum, nossa responsabilidade" & $\begin{array}{l}\text { "Quero ver o direito brotar como fonte e correr a } \\
\text { justiça qual riacho que não seca" (Am 5.24). }\end{array}$ \\
\hline
\end{tabular}

Fonte: Elaborada pelos autores.

\section{CAMPANHA DA FRATERNIDADE 2016}

O texto base da Campanha da Fraternidade 2016 mencionou a questão do saneamento básico, às condições sociais das populações menos favorecidas e a necessidade de que haja participação da população junto ao poder público para que este elabore e execute programas de saneamento básico com o acompanhamento das suas metas, objetivos e planos. Leva também ao apelo para que a comunidade conheça sua casa, seu bairro, sua cidade, participando e exigindo que o tema saneamento básico se torne prioridade nos estados e municípios; educando para a sustentabilidade, conhecendo as estruturais legais existentes, tomando conhecimento dos recursos que devem ser aplicados na universalização dos serviços de saneamento básico, sendo este um direito humano, a que todas as pessoas devem ter acesso. Ações como a diminuição e separação dos resíduos, reuso da água, reciclagem e o depósito dos resíduos coletados, que sejam feitos em aterros sanitários urbanos.

\section{MÉTODO}

Para este estudo utilizou-se de consulta e análise de documentos oficiais da Igreja Católica sobre educação e documentos que nortearam a Campanha da Fraternidade 2016, além dos materiais impressos utilizados pelos voluntários na realização dos encontros de 
conscientização sobre as questões ambientais durante a Campanha da Fraternidade do ano de 2016, e consultas a sites específicos, como o disponibilizado pela CNBB.

\section{RESULTADOS}

A Igreja Católica como instituição de grande influência na sociedade por sua abrangência, capacidade de unicidade mundial e número de segudidores em todo o mundo, também se faz presente de modo expressivo no Brasil, um dos maiores países católicos do mundo (123.280.172 fiéis, conforme o censo do IBGE de 2010), e divulga seus documentos e suas instruções por meio de órgãos como a CNBB se fazendo presente em todo o Brasil por meio de suas paróquias que contam com grande número de voluntários a serviço da evangelização e do trabalho social.

Ao expressar-se sobre a educação na 30a Assembleia Geral dos bispos do Brasil em 1992, a CNBB (2014, p. 62) aponta para uma educação evangélico-libertadora, onde o educando seja sujeito do próprio desenvolvimento e do desenvolvimento social, aprofundando a consciência da dignidade humana e o seu sentido comunitário, na formação para o serviço, ou seja, aquele que se educa tem por responsabilidade educar o próximo. Tem suas bases na educação libertadora que estabelece a presença crítica das pessoas, conforme Freire (1983, p.135). Segundo o documento da CNBB, esta forma de educação permite instrumentos de transformação social, criando uma nova maneira de ser, de viver e de conviver, tendo uma prática essencialmente dialógica. A teoria da ação dialógica (FREIRE, 1983) é um processo que envolve a colaboração, a união, a organização e a síntese cultural. A colaboração estabelece o encontro dos sujeitos para a leitura e pronúncia do mundo para a sua transformação e isto ocorre na comunicação. Já a união e a organização são ações culturais mediadas pela liderança e a síntese cultural dá-se na integração das pessoas, atores da ação exercida para a transformação do mundo.

Tendo como objetivo final a transformação social o trabalho educativo da igreja é revisado a partir das necesidades dos grupos sociais historicamente colocados à margem da vida social, econômica, política e cultural e religiosa, enfatizando-se sempre a valorização do ser humano e da vida digna para todos, expressando-se na busca da igualdade. $\mathrm{O}$ documento (CNBB, 2014, p.17) enfatiza a necessidade da mudança na educação que visa à preparação de mão-de-obra para o mercado, ou com finalidade técnico-lucrativa e não evidenciar o papel humano do trabalhador e o sentido cultural do trabalho. Defende uma 
educação de transformação social e não uma educação que seja para perpetuação da exclusão e a exploração do trabalho de muitos para o lucro de poucos.

Seguindo-se estas premissas a campanha da fraternidade de 2016, baseou-se na Encíclica do Sumo Pontífice Francisco, Laudato Si' (Louvado sejas: sobre o cuidado da casa comum). O documento discute a necessidade da união do progresso tecnológico com um progresso social e moral, os prós e contras da globalização, o antropocentrismo, a necessidade de alteração nos padrões de consumo e mudança no estilo de vida, o apelo para a renovação do diálogo sobre o futuro do planeta, enfatizando questões como poluição, mudanças climáticas, água, perda da biodiversidade, deteriorização da qualidade de vida humana e degradação social, desigualdade planetária, fraquezas das relações entre os países e diversidade de opiniões. O documento afirma que a análise dos problemas ambientais é inseparável da análise dos contextos humanos, familiares, laborais, urbanos, das relações de cada pessoa consigo mesma, que gera um modo específico de se relacionar com os outros e com o meio ambiente (p.87). Apresenta como orientação o pensar e agir tendo em mente a ecologia integral, ou seja, ecologia ambiental, social e econômica, sendo que as buscas de soluções envolvem uma abordagem integral para combater a pobreza, desenvolver a dignidade aos excluídos e, simultaneamente cuidar da natureza.

Uma segunda premissa abordada pelo documento diz respeito à valorização e cuidado com a cultura local, salvaguardando sua identidade original. Destaca ainda que a ecologia e a vida cotidiana expressam a relação do meio ambiente com a construção de identidade individual, afirmando a necessidade de uma harmonia ambiental para que construa uma harmonia individual, e vice e versa, num processo denominado ecologia humana que indica que o aceitar, respeitar e cuidar do próprio corpo reflete no cuidar e respeitar o ambiente, sendo que o contrário, a não-aceitação, o não amor e o não respeito consigo leva o ser humano a um desrespeito para com a natureza e com tudo aquilo que o rodeia, enfatizando a justiça intergeracional entendida como a noção de bem comum entre as gerações, já trazida no bojo do conceito de desenvolvimento sustentável, ou seja, a preocupação com as gerações futuras.

O documento Louvado Sejas, enfatiza a necessidade de mudança da sociedade em relação a sua consciência de origem comum, de recípoca pertença e de futuro compartilhado por todos. O desenvolvimento desta consciência desenvolverá novas convicções, novas atitudes e novos estilos de vida, sendo um desafio cutural, espiritual e educativo que resultará em uma regeneração ao longo do processo. 
Estas mudanças referem-se a um novo estilo de vida, menos consumista em que a liberdade não está em comprar aquilo que se quer, mas na escolha consciente e reflexiva daquilo que realmente se faz necessário para a vivência digna, onde o consumo não será uma forma de suprir insatisfações geradas por uma lógica de consumo desenfreado. A educação deverá ser voltada para a aliança entre a humanidade e o ambiente, onde a educação ambiental seja capaz de atuar em distintos níveis de equilíbrio ecológico, iniciando-se no interior do ser humano, passando para a interação solidária, com os outros e depois, o natural, ou seja, a interação com todos os seres vivos, e o espiritual, com Deus.

A responsabilidade ambiental é definida não só como um ato responsável, mas vai além, é um ato de amor, que como afirma Freire (1983, p. 94) possibilita o compromisso com os homens e sua causa, havendo a necessidade de um amor civil e político, onde se reconheça a necessidade de conviver uns com os outros, para com os quais se tem responsabilidades e consequentemente esta responsabilidade estende-se sobre a casa comum, ou seja, o espaço coletivo.

Para Moisés (2010) esta responsabilidade no contexto da saúde e saneamento básico é compreendida como uma prática social que demanda não só mudança de hábitos, práticas e atitudes, e a transmissão e construção de conhecimentos e exige também uma mudança na forma de pensar, sentir e agir e isso de dá por meio de seleção e utilização de métodos pedagógicos participativos e problematizadores, buscando-se um processo contínuo de indagação, reflexão, questionamento e, principalmente, de construção coletiva, articulada e compartilhada. Para o enfrentamento de questões de saneamento básico e, consequentemente, de saúde é necessário obter condições para identificar, conhecer, analisar e avaliar a questão apresentada e estar sensibilizado, capacitado e fortalecido para a consciência dessa realidade, participando das decisões para modificá-la, reconhecendo seu papel transformador e criador, colaborando de forma efetiva na solução e/ou encaminhamentos de problemas.

A educação como processo de formação dinâmico, transformador, abrangente, permanente e participativo, no qual as pessoas envolvidas passem a serem agentes transformadores, participando ativamente tanto do diagnóstico dos problemas, do planejamento, da execução, do monitoramento e avaliação das ações, da busca de alternativas e da implantação de soluções é essencialmente importante.

Durante a Campanha da Fraternidade que é realizada pela Igreja Católica durante o período da Quaresma (40 dias antes da Páscoa) a interação com a comunidade é realizada por meio de encontros com apoio de material editados pela CNBB para a Campanha da 
Fraternidade. Estes encontros são realizados, geralmente, nas casas, integrando os vizinhos que se reúnem, alternando o local a cada encontro. Na edição de 2016 o material analisado apresentou cinco encontros e a via-sacra, que rememora a paixão e morte de Cristo. A análise do material é apresentada a seguir, com seus temas e propostas de discussão, dividida por encontros.

No primeiro encontro foi abordado a importância da união de todas as religiões (ecumenismo), enfatizando a valorização e o respeito. No segundo encontro o objetivo apresentado foi o de conscientizar sobre a casa comum e a ameaça sobre ela, assim como a necessidade de ação e a responsabilidade para com o cuidado com o Planeta Terra, um chamado à ação e à defesa do planeta, inclusive com a denúncia dos crimes ambientais de que se tem conhecimento.

No terceiro encontro foi apresentado um chamado a ser profeta, denunciando os erros e auxiliando na busca da conversão e refletindo sobre a própria ação em relação à natureza.

No quarto encontro o objetivo foi de conscientizar da importância do saneamento básico para condições dignas de vida; reflexões sobre a união do homem e a natureza. $\mathrm{O}$ material afirmou que a desertificação deve ser considerada uma doença e a extinção de espécies, uma mutilação para cada ser humano. Atitudes em relação aos resíduos, à água, à energia elétrica, foram discutidas e apresentadas sugestões de ações práticas individuais e coletivas, como a realização de multirões.

No quinto encontro o objetivo foi mostrar o valor da vida humana, que, inúmeras vezes, é esquecido pelo valor exagerado atribuído aos bens materiais e ao consumismo. Reflete sobre a exclusão causada pelo não possuir bens materiais e a desvalorização da pessoa em detrimento a valorização do consumo.

$\mathrm{Na}$ via-sacra foram enfatizados o desenvolvimento da cultura do cuidado com o meio ambiente e a mudança de estilo de vida. Discussões sobre o sofrimento com a degradação da natureza, os poluentes que afetam a saúde, a união de todos para a mudança e o cuidado com a vida, a luta pelo saneamento básico, e a saída do egoísmo para viver de modo a usar somente o necesssário chamou os educadores para uma educação ecológica. Refletiu-se sobre os efeitos da corrupção que impede práticas sustentáveis e suscita para o arrependimento pelos erros em relação ao meio ambiente e a necessidade de mudança no estilo de vida, hábitos e valores que não auxiliam no cuidado da casa comum. 


\section{DISCUSSÕES}

A pedagogia da igreja católica estrutura-se sobre alguns conceitos baseados e interligados com os ensinamentos cristãos. Nesta pedagogia o ser humano é reconhecido como criação de Deus e goza de maior privilégio diante dos demais seres, por possuir racionalidade. No entanto, este privilégio significa maior responsabilidade sobre o cuidado em relação a todos os outros seres, inclusive aqueles que lhes são iguais. Percebe-se também a influência de Paulo Freire e a Pedagogia do oprimido que enfatiza a educação feita com as pessoas e não para elas, onde os problemas e necessidades são objeto de reflexão que resultará no engajamento para a transformação.

Os documentos analisados afirmam que o cuidado com a natureza provém do cuidado com o próprio ser humano que se insere no Meio Ambiente, e seu equilíbrio psicológico, visto que se não houver a consciência do cuidado consigo mesmo não poderá haver consciência do cuidado com o planeta, colaborando com o dever de desenvolver a partir do desenvolvimento individual um caráter social em sua relação com a natureza e com os outros seres humanos explicitado nas Diretrizes Curriculares Nacionais para a Educação Ambiental (2012).

A educação ambiental realizada pela igreja católica tem o diferencial de atingir um grande público devido ao número de fiéis presentes no Brasil. Importante notar que este atingimento não se restringe a faixa etária ou classe social, sendo uma educação ambiental que penetra e encontra aderência entre jovens, crianças, adultos e idosos, incluindo desde donas de casa a empresários, estudantes e profissionais liberais.

Os materiais desenvolvidos para o trabalho de conscientização apresentam temas sempre interligados ao cuidado ambiental e a justiça social, defendendo que não há preservação dos recursos naturais se não houver o respeito ao ser humano a começar por si próprio e aqueles que convivem diretamente.

Outra questão que se coloca por meio dos materiais de trabalho da Campanha da Fraternidade é a necessidade de atuação política do cristão para a defesa, tanto do meio ambiente como das condições sociais necessárias à vida digna para todos. E esta atuação na política deve se dar por meio de acompanhamento das ações do poder público em relação a programas para melhoria da vida das pessoas e do meio ambiente, além da participação direta por meio de cristãos engajados como prefeitos, vereadores e demais cargos públicos. 
A educação ambiental deve ser um processo educativo eminentemente político, desenvolvendo a consciência crítica acerca das instituições, atores e fatores sociais geradores de riscos e conflitos socioambientais, empoderando para o enfrentamento de tais conflitos por meio do exercício da cidadania e criação de demandas por políticas públicas participativas (LAYRARGUES, 2002) em que o cidadão responsabilize-se publicamente sobre os demais cidadãos e sobre a natureza, defendendo a vida humana e as outras formas de vida.

Diretrizes educacionais para a educação ambiental enfatizam que a principal função do trabalho com o tema Meio Ambiente é contribuir para a formação de cidadãos conscientes, aptos a decidir e atuar na realidade socioambiental de um modo comprometido com a vida, com o bem-estar de cada um e da sociedade, local e global (PCN, 1997) e isso é desenvolvido pela Igreja Católica por meio de suas campanhas, firmando-se como educadora ambiental, conforme afirmam Gerra e De Bastiane (2012).

Os materiais trazem uma reflexão ligada à ação transformadora, o convite à ação como uma responsabilidade, visto que como afirma Freire (1983, p. 57) a reflexão, se realmente, reflexão, conduz à prática. É possível afirmar, a partir da análise dos documentos, que a Igreja Católica enfatiza a responsabilidade pessoal e individual para consigo, com o outro e com o planeta. Rodrigues (2010) afirma que a Igreja Católica, reconhecendo a importância das questões suscitadas pelos movimentos ambientalistas e a partir de reflexões sobre a problemática do desenvolvimento, sugere o conceito de desenvolvimento humano integral, que se apresenta como a alternativa humanista cristã do desenvolvimento sustentável.

A instituição possui grande número de voluntários a seu serviço e para atuarem nos encontros da Campanha da Fraternidade receberam formação por meio de reunião com especialista no assunto abordado, também voluntários a serviço da instituição, além de acesso a materiais formativos para a condução dos encontros de acordo com a prática pedagógica adequada.

Desta forma, a análise dos documentos que embasaram a ação educativa da igreja em relação ao meio ambiente por meio da Campanha da Fraternidade de 2016, demonstrou o comprometimento da instituição na formação das pessoas para uma atitude responsável em relação ao meio ambiente e à sociedade, defendendo a vida humana e as outras formas de vida. 


\section{CONSIDERAÇÕES FINAIS}

A consciência, os valores humanos e ecológicos são primordiais para uma tomada de decisão eficiente quanto a preservação da natureza humana e, consequentemente, da própria socidade contemporânea. A alteração no estilo de vida consumista se inicia com uma profunda reflexão e concientização da importâcia do ser humano na preservação da natureza e da vida na terra.

A Igreja Católica atua na defesa dos direitos sociais, humanos e ecológicos e em muitos momentos históricos encontrou resistência nas políticas econômicas e sociais para exercer este papel fundamental.

A Campanha da Fraternidade 2016 evidencia as causas e mostra caminhos de atuação com o tema "Casa Comum", onde todos partilham o mesmo espaço e as consequências das ações atuais será o legado para as futuras gerações e também para a geração presente. Em documentos, a CNBB aponta para uma mudança de modelos educacionais, com uma abordagem evangélico-libertadora, atribuíndo ao educando responsabilidade em sua formação como sujeito do próprio desenvolvimento e do desenvolvimento social, afirmando que aquele que se educa tem a responsabilidade educar o outro.

Assim sendo, a Igreja Católica ao mesmo tempo em que aponta os problemas ecológicos e sociais, indica caminhos e possíveis soluções destacando a necessidade de empenho dos governantes e investimentos conscientes em áreas específicas da sociedade, além de atos reflexivos da população. Destaca que além da conscientização ambiental, é urgente a consciência social às mudanças necessárias do ser humano, como sujeito e autor em constante busca da construção do conhecimento social, ambiental e humano.

Uma mudança na maneira de pensar, sentir e agir, empregando-se métodos contínuos de indagação, reflexão, questionamento, em permanente construção coletiva, sistematizada e participativa, na qual os envolvidos sejam agentes transformadores, envolvendo-se efetivamente no diagnóstico dos problemas, no planejamento, na execução, no monitoramento e avaliação das ações, na busca de alternativas e na implantação de soluções.

\section{REFERÊNCIAS}

BIANCONI, M. L.; CARUSO, F. Educação não-formal. Cienc. Cult., 2005, v. 57, n.4, p.20-20. 2005.

BULLA, L. C. Relações sociais e questão social na trajetória histórica do serviço social brasileiro. Revista Virtual Textos \& Contextos, v. 2, nº 2, dez. 2003. 
CNBB Conferência Nacional dos Bispos do Brasil. Educação, Igreja e Sociedade. Ed. Paulinas, São Paulo. 7 ed. 2014.

CNBB. Texto base da Campanha da Fraternidade 2016. Disponível em < http://campanhas.cnbb.org.br/wp-content/uploads/2015/02/textobase2016.pdf> Acesso em 19 fev 2016.

FBOMS - Fórum Brasileiro de ONGs e Movimentos Sociais para o Meio Ambiente e o Desenvolvimento. A importância da Política e do Plano Nacional sobre Mudança do Clima e as interfaces com ações desenvolvidas pelos movimentos sociais e organizações ambientais. Revista FBMC, ano 1, p. 31-33, 2008.

FRANCISCO. Carta encíclica do Sumo Pontífice. Louvato Si' Louvado Sejas: sobre o cuidado da casa comum. Documento do magistèrio. Ed Paulus, São Paulo, 2015.

FREIRE, P. Pedagogia do oprimido. $13^{\circ}$ ed. Rio de Janeiro: Paz e Terra, 1983. 218 p.

GOHN, Maria da Glória. Educação não-formal na pedagogia social.. In: I CONGRESSO INTERNACIONAL DE PEDAGOGIA SOCIAL, 1., 2006, . Proceedings online... Faculdade de Educação, Universidade de São Paulo. Disponível em: < http://www.proceedings.scielo.br/scielo.php?pid=MSC0000000092006000100034\&script=sci_artt ex>. Acesso em 26 Set. 2016.

GUERRA, R. S., DE BASTIANE, T. M. Igreja Católica: uma educadora ambiental? REMOA, v. 5, n.5, p. 958-964, 2012.

IPCC. Climate Change 2014: Impacts, Adaptation, and Vulnerability. Part A: Assessment Report of the Global and Sectoral Aspects. Contribution of Working Group II to the Fifth Intergovernmental Panel on Climate Change. Cambridge University Press, Cambridge, United Kingdom and New York, NY, USA, 2014, 1132 p.

JACOBI, P. Educação ambiental, Cidadania e Sustentabilidade. Cadernos de Pesquisa, n. 118, p. 189-205, 2003.

LAYRARGUES; P.P. Crise ambiental e suas implicações na educação, 2002.

LEÃO XII, Papa. Carta encíclica «Rerum Novarum». Sobre a condição dos operários, 1891. Disponível em http://w2.vatican.va/content/leo-xiii/pt/encyclicals/documents/hf_lxiii_enc_15051891_rerum-novarum.html. Acesso em 22 fev 2016.

LIEFLANDER, A. Effectiveness of environmental education on water: connectedness to nature, environmental attitudes and environmental knowledge. Environmental Education Research, 2014.

MINISTÉRIO DA EDUCAÇÃO. Diretrizes Curriculares Nacionais para a Educação Ambiental, 2012. Disponível em <http://portal.mec.gov.br/dmdocuments/publicacao13.pdf>. Acesso em 01 agosto 2016.

MIRANDA, E.S.; SCHALL, V. T.; MODERNA, C. M. Representações sociais sobre educação ambiental em grupos da terceira idade. Ciência \& Educação, v. 13, n. 1, p. 15-28, 2007.

MOISÉS, M.; KLIGERMAN, D. C.; COHEN, S. C.; MONTEIRO, S. C. F. A política federal de saneamento básico e as iniciativas de participação, mobilização, controle social, educação em saúde e ambiental nos programas governamentais de saneamento. Ciência \& Saúde Coletiva, v. 15, n.5, p.2581-2591, 2010.

RODRIGUES, V. J. C. B. A Igreja Católica e o desenvolvimento sustentável. Revista Ciências da religião - história e sociedade, v. 8, n.1, p.198-233, 2010.

SAITO, C. H; RUSCHEINSKY, A./ BASTOS, F. P.; NUNES, J. B. A.; SILVA, L. F.; CARVALHO, L. M. Conflitos Socioambientais, Educação Ambiental e Participação Social na Gestão Ambiental. Sustentabilidade em Debate - Brasília, v. 2, n. 1, p. 121-138, 2011.

SECRETARIA DE EDUCAÇÃO FUNDAMENTAL. Parâmetros curriculares nacionais : meio ambiente / Secretaria de Educação Fundamental. - Brasília : MEC/SEF, 1997. 126p. Disponível em <http://portal.mec.gov.br/seb/arquivos/pdf/meioambiente.pdf>. Acesso em 01 agosto 2016.

ZAMBOM, R. E. A colaboração da igreja católica nos processos de lutas sociais no Brasil. In: I Simpósio Lutas Sociais na América Latina, 2005. Londrina - PR. Disponível em <http://www.uel.br/grupopesquisa/gepal/primeirosimposio/completos/rodrigoeduardozambon.pdf>. Acesso em 22 fev 2016. 